This is an electronic reprint of the original article. This reprint may differ from the original in pagination and typographic detail.

\author{
Author(s): Perros, A.; Bosund, M.; Sajavaara, Timo; Laitinen, Mikko; Sainiemi, L.; Huhtio, T.; \\ Lipsanen, $\mathrm{H}$.
}

Title: $\quad$ Plasma etch characteristics of aluminum nitride mask layers grown by lowtemperature plasma enhanced atomic layer deposition in SF6 based plasmas

Year: $\quad 2012$

Version:

Please cite the original version:

Perros, A., Bosund, M., Sajavaara, T., Laitinen, M., Sainiemi, L., Huhtio, T., \& Lipsanen, $H$. (2012). Plasma etch characteristics of aluminum nitride mask layers grown by lowtemperature plasma enhanced atomic layer deposition in SF6 based plasmas. Journal of Vacuum Science \& Technology A: Vacuum, Surfaces, and Films, 30(1), 11504. https://doi.org/10.1116/1.3664306

All material supplied via JYX is protected by copyright and other intellectual property rights, and duplication or sale of all or part of any of the repository collections is not permitted, except that material may be duplicated by you for your research use or educational purposes in electronic or print form. You must obtain permission for any other use. Electronic or print copies may not be offered, whether for sale or otherwise to anyone who is not an authorised user. 


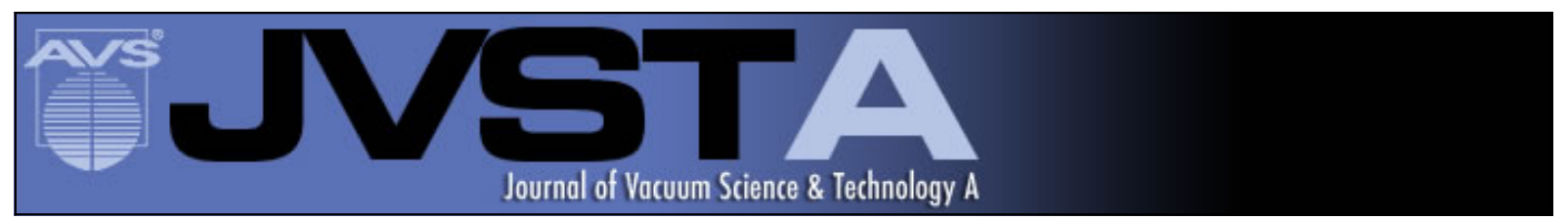

\section{Plasma etch characteristics of aluminum nitride mask layers grown by low-temperature plasma enhanced atomic layer deposition in SF6 based plasmas}

Alexander Perros, Markus Bosund, Timo Sajavaara, Mikko Laitinen, Lauri Sainiemi, Teppo Huhtio, and Harri Lipsanen

Citation: Journal of Vacuum Science \& Technology A 30, 011504 (2012); doi: 10.1116/1.3664306

View online: http://dx.doi.org/10.1116/1.3664306

View Table of Contents: http://scitation.aip.org/content/avs/journal/jvsta/30/1?ver=pdfcov

Published by the AVS: Science \& Technology of Materials, Interfaces, and Processing

\section{Articles you may be interested in}

Fabrication of AIN/BN bishell hollow nanofibers by electrospinning and atomic layer deposition

APL Mater. 2, 096109 (2014); 10.1063/1.4894782

Optical characteristics of nanocrystalline AlxGa1-xN thin films deposited by hollow cathode plasma-assisted atomic layer deposition

J. Vac. Sci. Technol. A 32, 031508 (2014); 10.1116/1.4870381

Bipolar resistive switching characteristics of low temperature grown $\mathrm{ZnO}$ thin films by plasma-enhanced atomic layer deposition

Appl. Phys. Lett. 102, 012113 (2013); 10.1063/1.4774400

Effect of in situ hydrogen plasma treatment on zinc oxide grown using low temperature atomic layer deposition J. Vac. Sci. Technol. A 31, 01A124 (2013); 10.1116/1.4767813

Crystal AIN deposited at low temperature by magnetic field enhanced plasma assisted atomic layer deposition J. Vac. Sci. Technol. A 31, 01A114 (2013); 10.1116/1.4764112

\section{HDDEN}

\section{Instruments for Advanced Science}

Contact Hiden Analytical for further details: W www.HidenAnalytical.com E info@hiden.co.uk CLICK TO VIEW our product catalogue

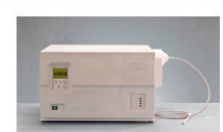

Gas Analysis dynamic measurement of reaction gas streams catalysis and thermal analysis molecular beam studies w, fermentation environmental and ecological studies

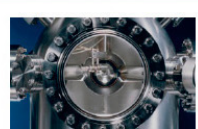

Surface Science

UHVTPD

SIMS emental imaging - surface mapping

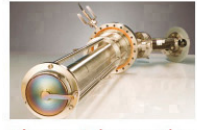

Plasma Diagnostics plasma source characterization etch and deposition process reaction analysis of neutral and radical species

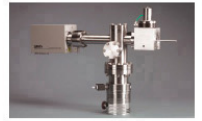

Vacuum Analysis partial pressure measurement and control of process gases reactive sputter process control , vacuum diagnostics vacuum coating process monitoring 


\title{
Plasma etch characteristics of aluminum nitride mask layers grown by low-temperature plasma enhanced atomic layer deposition in $\mathbf{S F}_{6}$ based plasmas
}

\author{
Alexander Perros ${ }^{\text {a) }}$ and Markus Bosund \\ Department of Micro- and Nanosciences, Aalto University School of Electrical Engineering, P.O. Box 13500, \\ FI-00076 Aalto, Finland \\ Timo Sajavaara and Mikko Laitinen \\ Department of Physics, University of Jyväskylä, P.O. Box 35, 40014, Jyväskylä,Finland \\ Lauri Sainiemi, Teppo Huhtio, and Harri Lipsanen \\ Department of Micro and Nanosciences, School of Electrical Engineering, Aalto University, P.O. Box 13500, \\ FI-00076, Aalto, Finland
}

(Received 6 April 2011; accepted 30 September 2011; published 5 December 2011)

\begin{abstract}
The plasma etch characteristics of aluminum nitride (AlN) deposited by low-temperature, $200{ }^{\circ} \mathrm{C}$, plasma enhanced atomic layer deposition (PEALD) was investigated for reactive ion etch (RIE) and inductively coupled plasma-reactive ion etch (ICP-RIE) systems using various mixtures of $\mathrm{SF}_{6}$ and $\mathrm{O}_{2}$ under different etch conditions. During RIE, the film exhibits good mask properties with etch rates below $10 \mathrm{rmm} / \mathrm{min}$. For ICP-RIE processes, the film exhibits exceptionally low etch rates in the subnanometer region with lower platen power. The AlN film's removal occurred through physical mechanisms; consequently, rf power and chamber pressure were the most significant parameters in PEALD AIN film removal because the film was inert to the $S F_{x}^{+}$and $\mathrm{O}^{+}$chemistries. The etch experiments showed the film to be a resilient masking material. This makes it an attractive candidate for use as an etch mask in demanding $\mathrm{SF}_{6}$ based plasma etch applications, such as through-wafer etching, or when oxide films are not suitable. (C) 2012 American Vacuum Society. [DOI: 10.1116/1.3664306]
\end{abstract}

\section{INTRODUCTION}

Aluminum nitride (AlN) has attracted great attention because of its attractive properties, including excellent chemical and thermal stability, a low thermal expansion coefficient close to that of silicon, a high thermal conductivity, and a wide band gap. AlN also has been studied as a nontoxic alternative to beryllium oxide ${ }^{1}$ and substitute to alumina for high temperature electronics. ${ }^{2}$ Sputtering and chemical vapor deposition (CVD) have been the traditional methods of deposition. Plasma enhanced atomic layer deposition (PEALD), which uses a plasma source to form radicals, expands the selection of atomic layer deposition (ALD) films, facilitates the deposition of nitride films, and can support lower deposition temperatures, higher deposition rates, and a higher degree of crystallization than the thermal ALD process. $^{3-5}$ AlN deposited by PEALD, as opposed to sputtered or CVD films, is well suited for demanding applications with sensitive substrates that require an extremely conformal pinhole free film with precise thickness control and large area scale up. ${ }^{6}$

The use of sputtered AlN as an etch mask for $\mathrm{SiO}_{2}$ during inductively coupled plasma-reactive ion etch (ICP-RIE) for a multitude of fluorine chemistries has already been studied. ${ }^{7}$ The material was shown to have a high selectivity to glass and a low etch rate. Sputtered AIN has also been investigated by Senensky and Pisano as a nonmetallic alternative masking material for the plasma etching of silicon carbide in $\mathrm{SF}_{6} / \mathrm{O}_{2}$ chemistries. ${ }^{8}$ In this article, the etch characteristics

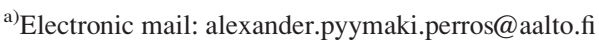

of PEALD AlN deposited at $200{ }^{\circ} \mathrm{C}$ for plasma etching processes using $\mathrm{SF}_{6}$ based chemistries are presented. Since aluminum has poor volatility in fluorine chemistry, the film is expected to have a good chemical resistance against $\mathrm{SF}_{6}$ chemistries. ${ }^{9}$ Of interest in this study was how AlN deposited by PEALD, which supports lower temperature growth than the thermal process, ${ }^{10}$ performs as an etch mask. This topic is relevant for applications that could utilize this method of deposition. Etching selectivity was not examined in this work.

\section{EXPERIMENTAL SETUP AND METHODOLOGY}

AlN films were deposited on 100 and $200 \mathrm{~mm}$ Si (100) substrates using a Beneq TFS-500 capacitively coupled remote plasma ALD reactor. Trimethylaluminum (TMA) and ammonia $\left(\mathrm{NH}_{3}\right)$ plasma were used as precursors, with nitrogen as the carrier gas, at a temperature of $200{ }^{\circ} \mathrm{C}$. The pulse/purge times were $0.8 \mathrm{~s} / 3 \mathrm{~s}$ and $15 \mathrm{~s} / 1 \mathrm{~s}$ for the TMA and $\mathrm{NH}_{3}$ plasma precursors, respectively. The flow rate for both precursors was $400 \mathrm{sccm}$. Prelssure was maintained at $\sim 1$ mbar. The rf plasma frequency was $13.56 \mathrm{MHz}$ and the plasma power was $50 \mathrm{~W}$. Plasma was turned on $1 \mathrm{~s}$ before and off $1 \mathrm{~s}$ after each $\mathrm{NH}_{3}$ pulse to ensure that a maximum number of reactive species were available. The deposition rate for AlN was $0.96 \AA /$ cycle. AlN films of $\sim 50, \sim 100$, and $\sim 150 \mathrm{~nm}$ thicknesses were deposited by PEALD for the reactive ion etch (RIE) and ICP-RIE experiments.

The RIE experiments were carried out in a Plasmalab 80 Plus parallel plate reactor at room temperature, while the ICP-RIE experiments were carried out in a Plasmalab 
System 100 reactor with He back-side cooling. Both systems are from Oxford Instruments. To establish if a temperature dependency on etch rates existed, experiments as low as $-90{ }^{\circ} \mathrm{C}$ were performed on the Plasmalab System 100. Temperature was not found to influence the etch characteristics of the AlN films; thus the results reported are limited to those conducted at roughly $15-20^{\circ} \mathrm{C}$. The samples used in the RIE experiments consisted of segments from an AlN coated $200 \mathrm{~mm}$ silicon wafer, while the ICP-RIE experiments used intact $100 \mathrm{~mm}$ wafers. Samples for the ICP-RIE experiments were loaded into the chamber via a loadlock to maintain good stability of the chamber vacuum and to increase the repeatability of the etch results. The wafers were mechanically clamped, and helium pressure was applied to the back-side of the wafer for cooling. Helium flow rates into the ICP-RIE chamber varied between 5 and $11 \mathrm{sccm}$ and did not appear to have a noticeable effect on etch rates. The rf on both systems operates at $13.56 \mathrm{MHz}$.

For the RIE experiments, $\mathrm{SF}_{6}$ and $\mathrm{O}_{2}$ flow rates and ratios were varied along with the bias power and pressure. For the ICP-RIE experiments, the gas compositions were fixed at 40 sccm $\mathrm{SF}_{6}$ and $6 \mathrm{sccm} \mathrm{O}_{2}$. Chamber pressure and rf power to the platen, which determines the bias between sample and plasma, were varied. The ability to separately control plasma density and bias between plasma and platen with the ICP-RIE system allows a high degree of reactive species independent of the platen power. This allows an additional degree of control between the physical and chemical component of etching not possible with RIE systems.

Film thickness and uniformity were measured by a Philips Plasmos SD 2300 single wavelength ellipsometer at a wavelength of $632.8 \mathrm{~nm}$ and angle of $70^{\circ}$. Ellipsometric measurements were performed after deposition and immediately before and after each etching step to determine the blanket etch rate. To ensure better accuracy of the ellipsometric results, only samples with measured thicknesses greater than $30 \mathrm{~nm}$ were considered. A nonuniform etch rate at the sample edge was observed and these areas were excluded from measurement by having an edge exclusion of $\sim 3 \mathrm{~mm}$ (mask etch uniformity is not addressed in the study). Repeated measurements showed no significant deviation. To confirm the ellipsometric measurements the cross sections of etched films were studied with a Zeiss SUPRA 40 scanning electron microscope.

The atomic concentrations of the film were determined by the time of flight elastic recoil detection analysis (TOFERDA) using $8.5 \mathrm{MeV}{ }^{35} \mathrm{Cl}^{+4}$ incident ions. ${ }^{11}$ The mass density was determined with a Philips X'pert Pro Diffractometer operating at the $\mathrm{Cu} K \alpha 1$ wavelength.

\section{RESULTS AND DISCUSSION}

\section{A. Film characterization}

In order to confirm that high-purity AIN films were deposited, elemental analysis was performed by TOF-ERDA on the films. The TOF-ERDA elemental depth profiles are presented in Fig. 1. The concentration of atoms in the bulk of the film, excluding the AlN surface and AlN/Si interface,

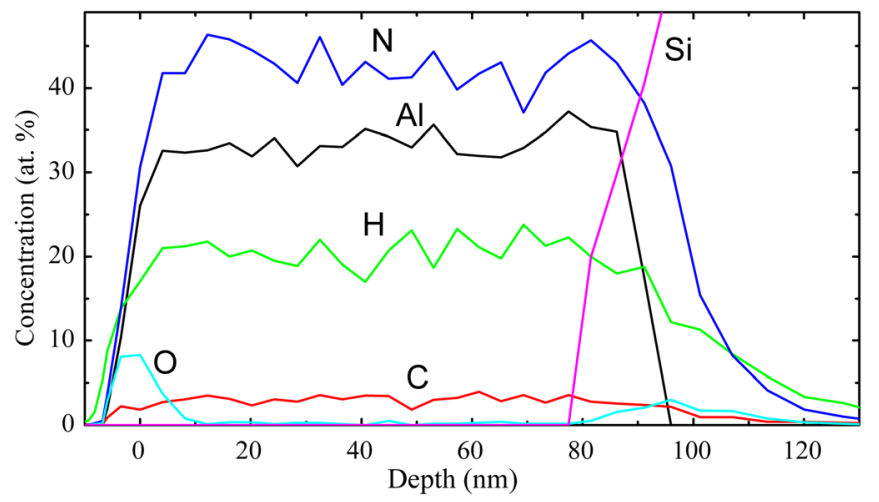

FIG. 1. (Color online) Elemental depth profiles of PEALD AIN film measured with TOF-ERDA.

is presented in Table I. The analysis revealed aluminum and nitrogen to exist at atomic concentrations of about 33 at. \% and 43 at. \%, respectively, with hydrogen making up almost the remaining $\sim 21$ at. $\%$ in the bulk of the film. The large hydrogen content of the film is important but expected of ALD AlN films deposited with $\mathrm{NH}_{3}{ }^{12-14}$ In general, hydrogen content has a significant effect on the properties of a film. ${ }^{15-17}$ Despite the high hydrogen content, the results demonstrate that the film performs well as an etch mask. Oxygen was incorporated at remarkably low concentrations with a small increase in oxygen concentration recorded at the immediate surface and the interface. Oxygen is known to form on the surface of AlN after exposure to air. ${ }^{18}$

The wet etch rates of AlN were measured for HF (20\%), $\mathrm{HCl}(37 \%)$, and $\mathrm{H}_{2} \mathrm{SO}_{4}(96 \%)$ aqueous etch solutions and found to be 56,9 , and $10 \mathrm{~nm} / \mathrm{min}$, respectively. The film was rapidly etched in AZ 351 developer, a caustic solution, at a rate of $\gg 100 \mathrm{~nm} / \mathrm{min}$. A PEALD AlN film with a thickness of $\sim 100 \mathrm{~nm}$ deposited on silicon is presented in Fig. 2 after patterning with developer AZ 351.

The film had a thickness variation of less than $1 \%$, a refractive index of $1.8-1.9$, and a density of $2.58 \mathrm{~g} / \mathrm{cm}^{3}$. This differs from stoichiometric AlN, which has a refractive index and bulk density of $2.094(\lambda=632.8 \mathrm{~nm})$ and $3.26 \mathrm{~g} / \mathrm{cm}^{3}$, respectively. ${ }^{19}$ Bosund et al., who analyzed PEALD AlN deposited with identical parameters and equipment as the film examined in this study, showed that the film's hydrogen content is responsible for this discrepancy in refractive index and density and, furthermore, demonstrated that the film is amorphous when deposited below $300{ }^{\circ} \mathrm{C}^{20}$ The authors

TABLE I. Concentration of atoms in the bulk of the PEALD AlN film as obtained from TOF-ERDA.

\begin{tabular}{lc}
\hline \hline Element & Concentration (at. \%) \\
\hline $\mathrm{H}$ & $21 \pm 4$ \\
$\mathrm{C}$ & $2.6 \pm 0.3$ \\
$\mathrm{~N}$ & $43 \pm 3$ \\
$\mathrm{O}$ & $0.25 \pm 0.10$ \\
$\mathrm{Na}$ & $0.13 \pm 0.05$ \\
$\mathrm{Al}$ & $33 \pm 3$ \\
\hline \hline
\end{tabular}




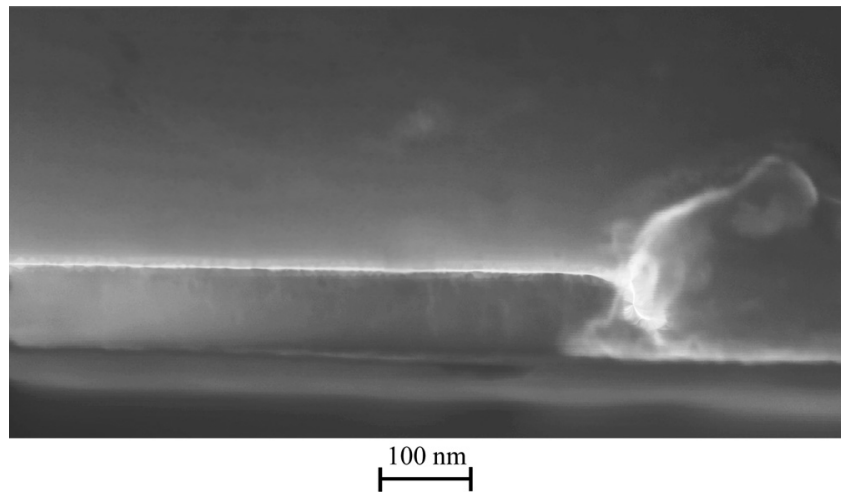

FIG. 2. PEALD AlN film of $100 \mathrm{~nm}$ thickness on silicon after patterning (etched region) in a caustic solution.

established a clear inverse correlation between the film's hydrogen content for both refractive index and density.

\section{B. RIE results}

In Figs. 3 and 4, the etch rate of $\mathrm{AlN}$ as a function of the oxygen percentage in $\mathrm{SF}_{6} / \mathrm{O}_{2}$ at 60 and $20 \mathrm{sccm}$, respectively, is shown with varying bias power and chamber pressure. At $60 \mathrm{sccm}$ it can be observed that the etch rate remains relatively constant irrespective of the compositions of oxygen, with only a slight increase observed at higher concentrations. There is some greater variability, however, observed when the flow rate is $20 \mathrm{sccm}$. Bias power plays the dominant role in the etching of the AlN film by controlling the electric field that accelerates the charged particles toward the wafer surface and the plasma density. When the process pressure is increased from 20 to $40 \mathrm{mTorr}$, a reduced etch rate is observed regardless of the $\mathrm{SF}_{6} / \mathrm{O}_{2}$ ratio and source power. By increasing the pressure, the energy and number of ions arriving on the wafer is decreased due to an increased number of collisions of ions with radicals and neutrals. ${ }^{21,22}$ Interestingly though, at this higher working pressure, a noticeable correlation between $\mathrm{O}_{2}$ percentage and

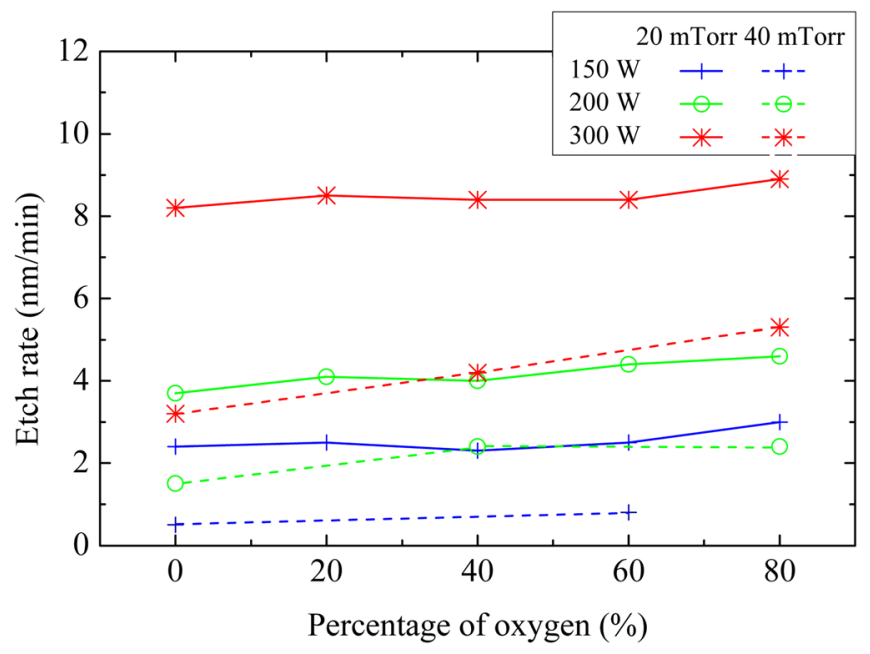

FIG. 3. (Color online) AlN etch rate in $\mathrm{SF}_{6}$ and $\mathrm{O}_{2}$, as a percentage of $\mathrm{O}_{2}$ at $60 \mathrm{sccm}$ at pressures of 20 and 40 mTorr for varying bias power.

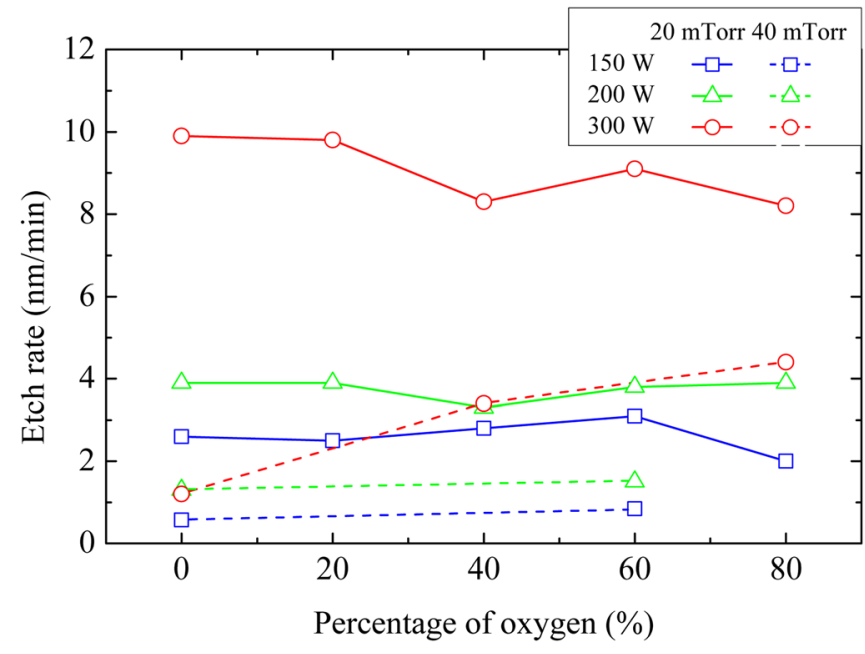

FIG 4. (Color online) AlN etch rate in $\mathrm{SF}_{6}$ and $\mathrm{O}_{2}$, as a percentage of $\mathrm{O}_{2}$ at $20 \mathrm{sccm}$ at pressures of 20 and $40 \mathrm{mTorr}$ for varying bias power.

etch rate emerges at least for $300 \mathrm{~W}$. Figure 5 illustrates this correlation and also shows that increasing oxygen content results in a higher rf peak bias for a fixed platen power level. This relationship is particularly pronounced at $20 \mathrm{sccm}$, where increased oxygen levels increase the etch rate. Goyette et al. showed that in addition to nearly all fluxes of significant ions increasing monotonically with power, an addition of $\mathrm{O}_{2}$ results in higher fluxes of $\mathrm{O}^{+}$and $\mathrm{SF}_{5}^{+} \cdot{ }^{23}$ The higher flux of these ions resulting from the addition of $\mathrm{O}_{2}$ causes more ion bombardment of the surface and could explain the observed correlation. It is assumed that these effects become more apparent at the higher working pressure, though a weak correlation can also be seen at the lower pressure when the flow rate is $60 \mathrm{sccm}$.

The bias power dependence of the etch rate is illustrated in Fig. 6 for varying $\mathrm{SF}_{6} / \mathrm{O}_{2}$ ratios at $60 \mathrm{sccm}$ to further illustrate the correlation between the two. With higher bias power, the etching takes place at an increased rate by increasing the plasma density. Consequently, the number of charged particles bombarding the surface is increased as well as the energy of these impinging ions. It should be

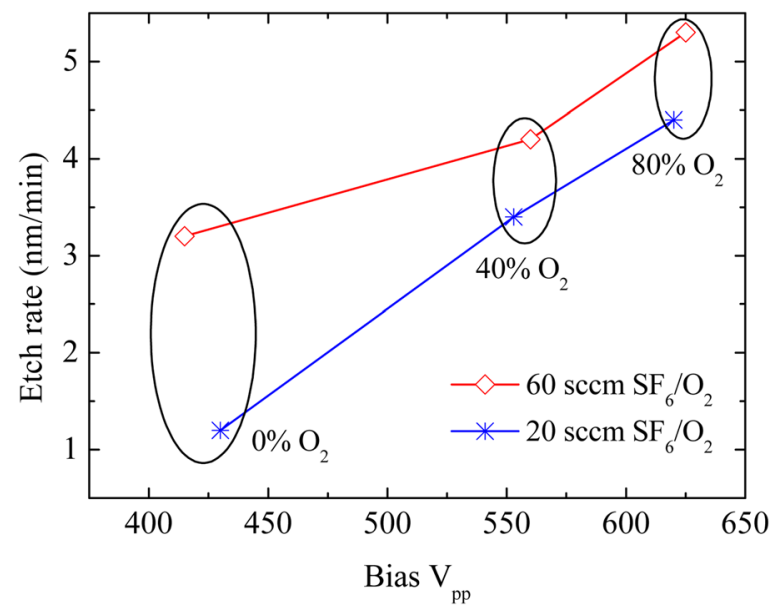

FIG. 5. (Color online) AlN etch rate in $\mathrm{SF}_{6}$ and $\mathrm{O}_{2}$, as a percentage of $\mathrm{O}_{2}$ at 20 and $60 \mathrm{sccm}$ at a pressure of $40 \mathrm{~m}$ Torr when bias power is $300 \mathrm{~W}$. 


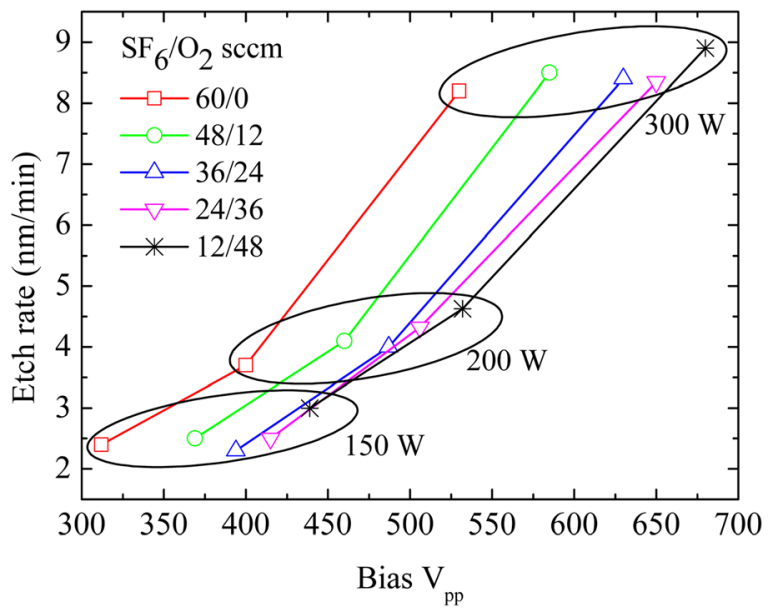

FIG. 6. (Color online) AlN etch rate in $\mathrm{SF}_{6} / \mathrm{O}_{2}$ as a function of $\mathrm{rf}$ peak bias voltage for different oxygen compositions at $60 \mathrm{sccm}$ and $20 \mathrm{mTorr}$. Applied bias power is also labeled.

noted that increasing the oxygen content for a given bias power increases the rf bias voltage considerably, though the effects on etch rate are minimal at 20 mTorr except at higher $\mathrm{O}_{2}$ levels, where, as mentioned earlier, a slight increase is observed.

These results seem to indicate that the main etch mechanism for AlN is physical rather than chemical for the $\mathrm{SF}_{6} / \mathrm{O}_{2}$ chemistries. The ICP-RIE results that follow provide greater insights into the matter of the dominant etch mechanism.

\section{ICP-RIE results}

For the ICP-RIE of AIN the etch rates are presented in Fig. 7 for a range of platen power levels at 10 and 20 mTorr of chamber pressure. The etch rate of AlN increases with platen power and lower pressure. The increase is due to the ions $\left(\mathrm{SF}_{x}^{+}\right.$and $\left.\mathrm{O}^{+}\right)$being accelerated at greater rates, which in turn break the bonds of AIN more easily. Lower pressure increases the mean free path of ions as intermolecular collisions are reduced. This means there is less energy loss of ions when they reach the surface of the film. By reducing the platen power, the physical component of etching is

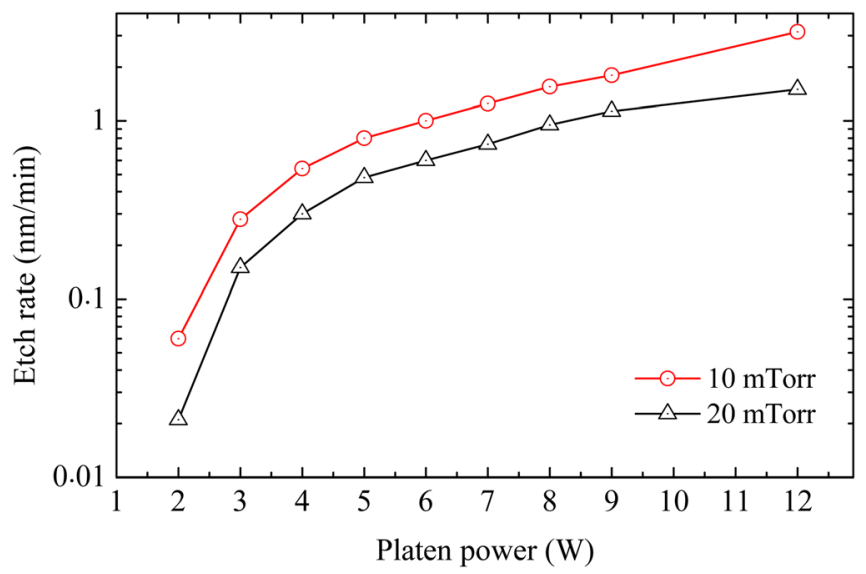

FIG. 7. (Color online) AlN etch rates as a function of platen power for ICPRIE. (40 sccm SF 6 , $6 \mathrm{sccm} \mathrm{O}, 5-11 \mathrm{sccm} \mathrm{He}, 1000$ W ICP). diminished, resulting in a marked reduction in etch rate. These results indicate that $\mathrm{AlN}$ is essentially inert to $S F_{x}^{+}$ and $\mathrm{O}^{+}$chemistry and is removed primarily by ion bombardment, thereby making the film's etch rate less pronounced at lower platen power levels. These results are to be expected as the involatile species $\mathrm{AlF}_{3}$, which forms on AlN's surface in fluorinated chemistries, acts as a protective coating that inhibits etching. ${ }^{24,25}$

\section{SUMMARY AND CONCLUSIONS}

The plasma etch characteristics of AIN deposited by PEALD at $200{ }^{\circ} \mathrm{C}$ were investigated for RIE and ICP-RIE systems for $\mathrm{SF}_{6}$ and $\mathrm{O}_{2}$ chemistries. For the RIE experiments, bias power, flow rate, and chamber pressure were varied for different ratios of $\mathrm{SF}_{6}$ and $\mathrm{O}_{2}$. Etch rates below $10 \mathrm{~nm} / \mathrm{min}$ were observed with the bias power and chamber pressure playing the most significant roles. The oxygen level plays a minor role in the etch rates until the pressure is raised from 20 to 40 mTorr when bias power is $300 \mathrm{~W}$. Under these conditions increased oxygen levels result in an increased etch rate.

For the ICP-RIE experiments, the $\mathrm{SF}_{6} / \mathrm{O}_{2}$ gas mixture was fixed at 40 and $6 \mathrm{sccm}$, respectively, with platen power and chamber pressure varying. The film exhibited exceptionally low etch rates in the subnanometer region when platen power was below $6 \mathrm{~W}$. The etch rates approached negligible levels the further the platen power was lowered. AlN was shown to be quite chemically inert to the $\mathrm{SF}_{6} / \mathrm{O}_{2}$ etch chemistry and is only etched by the physical mechanisms associated with plasma etching.

The suitability of low-temperature PEALD AIN as an etch mask in demanding plasma etch applications has been demonstrated, and it was shown that the film can serve as an attractive alternative to other resilient masking films.

\section{ACKNOWLEDGMENTS}

The authors would like to acknowledge the Finnish Agency for Technology and Innovation (TEKES ALDUEX project) for providing financial support. The authors also acknowledge Aalto University at Micronova for provision of cleanroom facilities.

${ }^{1}$ M. Kettner, P. Biebersmith, N. Roldan, and B. K. Sharma, Microwave J. 44, 104 (2001).

${ }^{2}$ N. Chasserio, S. Guillemet-Fritsch, T. Lebey, and S. Dagdag, J. Electron. Mater. 38, 164 (2009).

${ }^{3}$ M. Leskelä and M. Ritala, Thin Solid Films 409, 138 (2002).

${ }^{4}$ J. W. Lim and S. J. Yun, Electrochem. Solid-State Lett. 7, F45 (2004).

${ }^{5}$ J. S. Park, H. S. Park, and S. W. Kang, J. Electrochem. Soc. 149, C28 (2002).

${ }^{6}$ R. L. Puurunen, A. Root, P. Sarv, M. M. Viitanen, H. H. Brongersma, M. Lindblad, and A. O. I. Krause, Chem. Mater. 14, 720 (2002).

${ }^{7}$ K. Kolari, Microelectron. Eng. 85, 985 (2008).

${ }^{8}$ D. G. Senesky and A. P. Pisano, 23rd IEEE International Conference on Micro Electro Mechanical Systems (MEMS), Wanchai, Hong Kong, 24-28 January 2010 (IEEE, New York, 2010), pp. 352-355.

${ }^{9}$ K. R. Williams and R. S. Muller, J. Microelectromech. Syst. 5, 256 (1996).

${ }^{10}$ X. Liu, S. Ramanathan, E. Lee, and T. E. Seidel, Mater. Res. Soc. Symp. Proc. 811, 11 (2004). 
${ }^{11}$ M. Putkonen, T. Sajavaara, L. Niinistö, and J. Keinonen, Anal. Bioanal. Chem. 382, 1791 (2005).

${ }^{12}$ J. Jokinen, P. Haussalo, J. Keinonen, M. Ritala, D. Riihela, and M. Leskela, Thin Solid Films 289, 159 (1996).

${ }^{13}$ D. Riihela, M. Ritala, R. Matero, M. Leskela, J. Jokinen, and P. Haussalo, Chem. Vap. Deposition 2, 277 (1996).

${ }^{14}$ Y. J. Lee and S.-W. Kang, Thin Solid Films 446, 227 (2004).

${ }^{15}$ S. S. Han, B. H. Jun, K. No, and B. S. Bae. J. Electrochem. Soc. 145, 652 (1998).

${ }^{16}$ T. H. Fang and W. J. Chang, Appl. Surf. Sci. 252, 6243 (2006).

${ }^{17}$ H. Wong and H. Iwai, Microelectron. Eng. 83, 1867 (2006).

${ }^{18}$ A. Weidinger, D. Nagengast, Ch. Rehm, F. Klose, and B. Pietzak, Thin Solid Films 275, 48 (1996).
${ }^{19}$ G. A. Slack and T. F. McNelly, J. Cryst. Growth 34, 263 (1976).

${ }^{20}$ M. Bosund, T. Sajavaara, M. Laitinen, T. Huhtio, M. Putkonen, V.-M. Airaksinen, and H. Lipsanen, Appl. Surf. Sci. 257, 7827 (2011).

${ }^{21}$ D. L. Flamm and G. K. Herb, in Plasma Etching, An Introduction, edited by D. M. Manos and D. L. Flamm (Academic, Boston, 1989), Chap. 1, pp. $1-90$.

${ }^{22}$ J. Liu, G. L. Huppert, and H. H. Sawin, J. Appl. Phys. 68, 3916 (1990).

${ }^{23}$ A. N. Goyette, Y. Wang, and J. K. Olthoff, J. Vac. Sci. Technol. A 19, 1294 (2001).

${ }^{24}$ K. L. Seaward, N. J. Moll, D. J. Coulman, and W. F. Stickle, J. Appl. Phys. 61, 2358 (1987).

${ }^{25}$ C. B. Cooper. S. Salimian, and H. F. MacMillan, Appl. Phys. Lett. 51, 225 (1987). 